\title{
Betanin effect on PPAR- $\alpha$ and SREBP-1c expression in NMRI mice model of steatohepatitis with fibrosis
}

\section{YAHAGHI ${ }^{1}$, PARICHEHREH YAGHMAEI ${ }^{1 *}$ (D) N. HAYATI-ROODBARI ${ }^{1}$, S. IRANI ${ }^{1}$ and A. EBRAHIM-HABIBI ${ }^{2,3}$}

${ }^{1}$ Department of Biology, Science and Research Branch, Islamic Azad University, Tehran, Iran

${ }^{2}$ Biosensor Research Center, Endocrinology and Metabolism Molecular-Cellular Sciences Institute, Tehran University of Medical Sciences, Tehran, Iran

${ }^{3}$ Endocrinology and Metabolism Research Center, Tehran University of Medical Sciences, Tehran, Iran

Received: February 12, 2019 • Accepted: December 20, 2019

Published online: April 14, 2020

(C) 2020 Akadémiai Kiadó, Budapest

\begin{abstract}
Purpose: Betanin is a betacyanin with antioxidant and anti-inflammatory activities whose effects were investigated in a nonalcoholic steatohepatitis (NASH) model. Main methods: Ninety-six male naval medical research institute (NMRI) mice were divided into eight groups $(n=12)$ including normal control, high fat diet (HFD), Sham, and positive control treated with trans-chalcone. Three experimental groups were treated with 5 $\mathrm{mg} / \mathrm{kg}, 10 \mathrm{mg} / \mathrm{kg}$ or $20 \mathrm{mg} / \mathrm{kg}$ betanin, and a betanin protective group was also defined. Results: Four weeks of HFD treatment resulted in steatohepatitis with associated fibrosis. Significant increase was observed in serum levels of triglycerides (TG), total cholesterol (TC), glucose, insulin, leptin, liver enzymes, malondialdehyde (MDA), furthermore insulin resistance and (sterol regulatory element-binding protein-1c) SREBP-1c were detected. Levels of high-density lipoprotein cholesterol (HDL-C), adiponectin, superoxide dismutase (SOD), catalase (CAT), and PPAR- $\alpha$ (peroxisome proliferator-activated receptor- $\alpha$ ) considerably decreased. Treatment by betanin, particularly the $20 \mathrm{mg} / \mathrm{kg}$ dosage, attenuated these changes. Conclusion: Betanin is a potential treating agent of steatohepatitis and works through up-regulation of PPAR- $\alpha$, down-regulation of SREBP-1c, modification of adipokine levels and modulation of lipid profile.
\end{abstract}

* Corresponding author. Shodada Hesarak blvd, Daneshgah Square, Sattari Highway, Tehran, 1477893855, Iran. Tel. +98 912 2010222; Fax: +98 21 22363520. E-mail: yaghmaei_p@srbiau.ac.ir 


\section{KEYWORDS}

betanin, nonalcoholic fatty liver disease (NAFLD), nonalcoholic steatohepatitis (NASH), peroxisome proliferatoractivated receptor- $\alpha$ (PPAR- $\alpha$ ), insulin resistance

\section{INTRODUCTION}

Non-alcoholic fatty liver disease (NAFLD) is a metabolic dysfunction that can progress to nonalcoholic steatohepatitis (NASH), fibrosis and cirrhosis. In the progression of NAFLD to NASH, various factors are involved such as triglyceride accumulation and oxidative stress [8].

Peroxisome proliferator activated receptors (PPARs) and sterol regulatory element-binding proteins (SREBPs) are important in the pathogenesis of NAFLD/NASH as they play a role in regulating fatty acid and cholesterol homeostasis via fatty acid oxidation and lipogenesis [21, 26]. In the liver, PPAR- $\alpha$ influences the genes related to fatty acid $\beta$-oxidation [36], inhibits the expression of inflammatory genes, and increases the expression of antioxidant-related genes [4, 41]. SREBP-1c is regulated by PPAR- $\alpha$ agonists [26]. Overexpression of SREBP-1c leads to accumulation of triglycerides (TG) in the liver to cause NAFLD [19].

Accordingly, antioxidants and free radical scavengers should possess therapeutic potential in the treatment of NASH [1]. Beetroot juice is used as a traditional treatment for liver diseases and for stimulation of the immune system [35]. Betanin (betanidin 5-O-b-D-glucoside) can be considered a main active ingredient with a principal role in the effects of beetroot [11].

Betanin structure includes phenolic and cyclic amine groups, which are good electron donors, and thus have a remarkable free-radical scavenging property. Antioxidant and anti-inflammatory properties of betanin [22], as well as inhibition of lipid peroxidation and the oxidation of low-density lipoproteins (LDL) have been reported [15].

The aim of this study was to assess the effect SOF betanin on biochemical and histological indicators, PPAR- $\alpha$ and SREBP-1c expression in NASH model.

\section{MATERIALS AND METHODS}

\section{Materials}

All materials were purchased from Sigma-Aldrich (Sigma-Aldrich, St. Louis, MO, USA) unless stated. Commercial kits were used for the evaluation of low-density lipoprotein cholesterol (LDL-C), high-density lipoprotein cholesterol (HDL-C), very low density lipoprotein (VLDL), TG, total cholesterol (TC), alanine aminotransferase (ALT), aspartate aminotransferase (AST), alkaline aminotransferase (ALP), and glucose in serum and provided from ZistChimi Chemical Company, Tehran, Iran. Serum leptin and adiponectin were measured with Mouse Leptin ELISA Kit from Yanaihara Institute Inc., Japan, and Mouse adiponectin ELISA kit by Otsuka Pharmaceutical Co., Japan respectively. Serum insulin assays were done with Mouse Ultrasensitive Insulin ELISA kit (ALPCO Diagnostics, USA). EnzyChrom ${ }^{\mathrm{TM}}$ Phospholipid Assay Kit (EPLP-100) (Belgium) was used for phospholipid assessment. The cytokine tumor necrosis factor-alpha (TNF- $\alpha$ ) level in serum was analyzed by Mouse TNF-alpha ELISA Kite Bioscience, USA. High Pure RNA Isolation Kit (Roche, Switzerland) was used for RNA isolation and Revert Aid First Strand cDNA Synthesis Kit (Thermo Scientific, USA) was used for cDNA synthesis. 
SYBR Green and primers used for the evaluation of PPAR- $\alpha$ and SREBP-1c genes expression were obtained from YektaTajhizAzma, Iran.

\section{Animals}

Male naval medical research institute (NMRI) mice weighing $25 \pm 5 \mathrm{~g}$ were purchased from the Pasteur Institute, Karaj, Iran. All animals were kept in the same room under standard conditions with a $12 \mathrm{~h}$ light/dark cycle at $22-24^{\circ} \mathrm{C}$ and had ad libitum access to standard pellet and water.

\section{Experimental protocol}

Animals were weighed and divided into the eight following groups ( $n=12$ in each group):

- Normal Control group: receiving a normal rodent diet (NC)

- High Fat Diet group: receiving a high fat regime (HFR) (details described below in 2.3.1 HFR) for 4 weeks (HFD)

- Sham group: receiving a HFR for 4 weeks and shifted to a NC with betanin solvent (Distilled water) by intra-peritoneum injection for 3 weeks

- Positive Control group: receiving a HFR for 4 weeks and shifted to a NC with trans-chalcone ( $24 \mathrm{mg} / \mathrm{kg}$ body weight) [17] by intra-peritoneum injection for 3 weeks (PC)

- Experimental group I, II and III: receiving a HFR for 4 weeks and shifted to a NC with 5, 10 and $20 \mathrm{mg} / \mathrm{kg}$ doses of betanin respectively, by intra-peritoneum injection for 3 weeks (eB1, $\mathrm{eB} 2$, and eB3)

Protective group: receiving a HFR alongside with high dose of betanin $(20 \mathrm{mg} / \mathrm{kg}$ body weight) administered by intra-peritoneum injection for 4 weeks (PB). A summary of the groups can be found in Supplementary Table I.

High fat regime. NAFLD was induced by oral gavage $(8 \mathrm{~mL} / \mathrm{kg} / \mathrm{day})$ of a liquid emulsion, (Supplementary Table II) and feeding simultaneously the animals with ad libitum HF diet (supplementary Table III) that consists of $43.11 \%$ fats $(1.12 \%$ cholesterol) and $0.18 \%$ fructose.

Treatment. Treatment was performed according to the experimental protocol for 3 weeks. The experimental protocol was performed in accordance with the international guidelines established in the Guide for the Care and Use of Laboratory Animals and further approved by the University's Internal Ethics committee (approval code: 176947).

\section{Histological and biochemical assay}

Blood serum preparation and analysis. Animals were anesthetized by inhalation of diethyl ether, after which a terminal blood sample was withdrawn from cardiac ventricles was performed. Blood samples were allowed to clot for $60 \mathrm{~min}$ at room temperature and then centrifuged at $3000 \mathrm{rpm}$ at $30{ }^{\circ} \mathrm{C}$ for $10 \mathrm{~min}$ to separate the serum. Insulin resistance index was evaluated by the homeostasis model assessment (HOMA) formula: HOMA = fasting serum insulin $(\mathrm{mU} / \mathrm{L}) \times$ fasting plasma glucose $(\mathrm{mM}) / 22.5$ [29]. The atherogenic index was calculated as follows: Atherogenic Index $(\mathrm{AI})=(\mathrm{TC}-\mathrm{HDL}-\mathrm{C}) / \mathrm{HDL}-\mathrm{C}$. 
Liver tissue staining. Liver tissues were removed and weighed, and their sections were immediately fixed in a $10 \%$ formalin buffer solution for histopathological evaluation. Tissues were embedded in paraffin and cross-sectioned into $5 \mathrm{~mm}$ sections according to routine protocols. Liver sections were stained with hematoxylin \& eosin (H\&E) and Masson's trichrome (MT). The slides were examined by light microscopy.

Liver homogenate preparation for antioxidant enzymes and biochemical assays. Liver tissue was also used for biochemical determination of catalase (CAT), superoxide dismutase (SOD), malondialdehyde (MDA) activities and LDL-C, HDL-C, VLDL, phospholipid, TG, TC, total lipid (TL) and total protein (TP) levels. First, tissue samples were frozen in liquid nitrogen until biochemical analyses were performed. They were homogenized $(1: 3, w / v)$ in phosphate saline buffer (pH 7.4). After homogenization, samples were sonicated for $1.5 \mathrm{~min}$ with bursts of $30 \mathrm{~s}$. All procedures were performed at $0-4{ }^{\circ} \mathrm{C}$. Homogenate samples were centrifuged at $22,000 \mathrm{~g}$ for 17 min at $4{ }^{\circ} \mathrm{C}$, in a microcentrifuge. The supernatant was frozen at $-40{ }^{\circ} \mathrm{C}$ until the time of assay. Levels of LDL-C, HDL-C, VLDL, phospholipid, TG, TC, TP, TL and activities of CAT, SOD, MDA were determined using commercially available kits.

\section{RNA analysis and CDNA preparation}

Total RNA was extracted from liver tissues by High Pure RNA Isolation Kit protocol of Roche (Switzerland). Purified RNA was stored at $-80^{\circ} \mathrm{C}$ for later analysis. cDNA synthesis was done with Thermo Scientific kit protocol. Real-time quantitative PCR (qPCR) was performed by YTA SYBR Green qPCR MasterMix 2X protocol (YektaTajhizAzma, Iran).

Primer sequences for SREBP-1c, PPAR- $\alpha$ and hypoxanthine guanine phosphoribosyl transferase (HPRT) (used as a housekeeping gene) were obtained from the National Center for Biotechnology Information (NCBI) website. Specific primers were designed by the Primer express program (shown in supplementary Table IV).

\section{STATISTICAL ANALYSIS}

One-way ANOVA was used, and the results were expressed as the mean \pm SEM (standard error of the mean) followed by Tukey's post hoc test (SPSS V.24, IBM Corporation, New York, USA). The level of statistical significance was set at $P<0.05$.

\section{RESULTS}

\section{Body weight}

Initially, there was no body weight difference between groups. After four weeks, body weight increase was less in the groups that received HFR vs. NC group. The NASH model group and the protective group were sacrificed at this time (Table 1). Weight difference was significant in HFD, Sham $(P<0.01)$ and PC $(P<0.05)$ groups vs. NC group. After removing HFR from mice diet, significantly lower body weight was still observed in Sham, eB1 and eB2 groups vs. NC group $(P<0.001)$, so that the NC group gained $\sim 1 \mathrm{~g}$, Sham lost $\sim 1 \mathrm{~g}, \mathrm{eB} 1$ and eB2 groups gained $0.62 \mathrm{~g}$ and $0.92 \mathrm{~g}$, respectively, during the 3 weeks of drug treatment, whereas the $\mathrm{PC}$ and $\mathrm{eB} 3$ 
Table 1. Comparison of body weights

\begin{tabular}{|c|c|c|c|c|c|c|c|c|}
\hline Groups & $\mathrm{NC}$ & HFD & Sham & PC & eB1 & eB2 & eB3 & $\mathrm{PB}$ \\
\hline Start week(g) & $\begin{array}{c}25.91 \pm \\
1.17\end{array}$ & $26.41 \pm 1.01$ & $25.33 \pm 0.66$ & $27.33 \pm 0.67$ & $25.66 \pm 0.39$ & $27.00 \pm 0.55$ & $27.58 \pm 0.59$ & $\begin{array}{c}27.70 \pm \\
0.37\end{array}$ \\
\hline $\begin{array}{l}\text { After } 4 \\
\text { week(g) }\end{array}$ & $\begin{array}{c}37.25 \pm \\
0.80\end{array}$ & $\begin{array}{l}31.25 \pm \\
0.87^{++}\end{array}$ & $31.08 \pm 0.65^{++}$ & $32.58 \pm 2.30^{+}$ & $32.25 \pm 0.54^{+}$ & $32.83 \pm 0.69$ & $33.12 \pm 0.71$ & $\begin{array}{c}33.37 \pm \\
0.64\end{array}$ \\
\hline Final week(g) & $\begin{array}{c}38.66 \pm \\
0.80\end{array}$ & - & $29.83 \pm 0.56^{+++}$ & $\begin{array}{l}39.08 \pm \\
0.66^{\# \# \#}\end{array}$ & $\begin{array}{l}32.87 \pm \\
0.66^{+++}\end{array}$ & $33.75 \pm \underset{\# \#}{1.03}$ & $\begin{array}{l}36.00 \pm \\
0.60^{\# \# \#}\end{array}$ & - \\
\hline
\end{tabular}

Data are expressed as means \pm SEM.

${ }^{+} P<0.05,{ }^{++} P<0.01,{ }^{+++} P<0.001$ vs. normal control group.

${ }^{* *} P<0.01,{ }^{* * *} P<0.001$ vs. HFD group.

${ }^{\#} P<0.05,{ }^{\# \#} P<0.01,{ }^{\# \#} P<0.001$ vs. Sham group. 
Table 2. Effects of betanin on serum biochemical parameters in HFR-fed mice

\begin{tabular}{|c|c|c|c|c|c|c|c|c|}
\hline Groups & NC & HFD & Sham & $\mathrm{PC}$ & eB1 & $\mathrm{eB} 2$ & eB3 & $\mathrm{PB}$ \\
\hline \multicolumn{9}{|l|}{ Parameters } \\
\hline $\mathrm{TG}(\mathrm{mg} / \mathrm{dL})$ & $71.14 \pm 2.25$ & $\begin{array}{l}136.25 \pm \\
2.85^{+++}\end{array}$ & $127.75 \pm 2.76^{+++}$ & $\begin{array}{l}78.91 \pm \\
0.98^{* * * * \# \# \#}\end{array}$ & $\begin{array}{c}115.60 \pm \\
1.77^{+++},{ }^{* * * * \# \#}\end{array}$ & 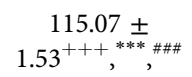 & 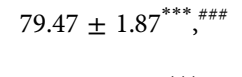 & $\begin{array}{c}87.49 \underset{*}{ \pm} \\
1.65^{+++},, \text {,\#\#\# }\end{array}$ \\
\hline $\mathrm{TC}(\mathrm{mg} / \mathrm{dL})$ & $\begin{array}{c}117.77 \\
3.52\end{array}$ & $\begin{array}{l}226.75 \pm \\
2.09^{+++}\end{array}$ & $226.25 \pm 4.57^{+++}$ & $\begin{array}{l}118.50 \pm \\
2.30^{* * * * \# \# \#}\end{array}$ & $\begin{array}{l}214.32 \pm \\
2.89^{+++}\end{array}$ & $\begin{array}{l}212.87 \pm \\
2.99^{+++}\end{array}$ & 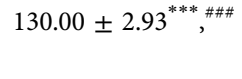 & $\begin{array}{c}155.36 \pm \\
2.76^{+++, * * *}, \# \# \#\end{array}$ \\
\hline $\begin{array}{l}\text { Phospholipid } \\
\text { (mg/dL) }\end{array}$ & $\begin{array}{c}182.57 \pm \\
1.94\end{array}$ & $\begin{array}{l}255.50 \pm \\
1.52^{+++}\end{array}$ & $255.17 \pm 3.33^{+++}$ & - & - & - & $\begin{array}{c}211.92 \pm \\
1.48^{+++, * * * * \# \# \#}\end{array}$ & $\begin{array}{c}212.40 \pm \\
0.98^{+++* * * * \# \# \#}\end{array}$ \\
\hline $\mathrm{TL}(\mathrm{mg} / \mathrm{dL})$ & $246.52 \pm 6.40$ & $461.42 \pm 7.55^{+++}$ & $446.57 \pm 13.39^{+++}$ & - & - & - & $\begin{array}{c}288.45 \pm \\
9.27^{+* * *}, \ldots \# \#\end{array}$ & $\begin{array}{c}325.65 \pm \\
4.10^{+++* * * \# \# \#}\end{array}$ \\
\hline $\begin{array}{l}\text { HDL-C (mg/ } \\
\qquad \mathrm{dL})\end{array}$ & $65.72 \pm 2.47$ & $34.07 \pm 1.12^{+++}$ & $39.85 \pm 1.52^{+++}$ & - & - & - & 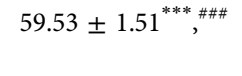 & $\begin{array}{c}57.16 \pm \\
0.98^{++* * * \# \# \#}\end{array}$ \\
\hline $\begin{array}{l}\text { LDL-C (mg/ } \\
\qquad \mathrm{dL})\end{array}$ & $38.32 \pm 3.38$ & $\begin{array}{l}126.55 \pm \\
3.49^{+++}\end{array}$ & $133.52 \pm 2.72^{+++}$ & - & - & - & $\begin{array}{c}90.16 \pm \\
0.95^{+++, * * * \# \# \#}\end{array}$ & $\begin{array}{c}94.67 \pm \\
0.93^{+++, * * * \# \# \#}\end{array}$ \\
\hline $\begin{array}{l}\text { VLDL (mg/ } \\
\quad \mathrm{dL})\end{array}$ & $13.74 \pm 0.53$ & $29.37 \pm 3.41^{+++}$ & $24.34 \pm 1.47^{+++}$ & $\begin{array}{l}16.03 \pm \\
0.26^{* * *} \text {, \#\#\# }\end{array}$ & $\begin{array}{l}23.12 \pm \\
0.35^{+++}\end{array}$ & $\begin{array}{l}22.95 \pm \\
0.32^{+++}\end{array}$ & $17.64 \pm 0.30^{* * * *}$ & $\begin{array}{l}18.24 \pm \\
0.39^{* * * * \#}\end{array}$ \\
\hline $\mathrm{TP}(\mathrm{mg} / \mathrm{dL})$ & $2.68 \pm 0.12$ & $4.30 \pm 0.12^{+++}$ & $4.17 \pm 0.16^{+++}$ & $\begin{array}{c}2.60 \pm \\
0.10^{* * * * \# \#}\end{array}$ & $4.58 \pm 0.09^{+++}$ & $4.63 \pm 0.07^{+++}$ & $4.02 \pm 0.04^{+++}$ & $3.93 \pm 0.15^{+++}$ \\
\hline FBS (mg/dL) & $\begin{array}{c}101.00 \pm \\
2.05\end{array}$ & $\begin{array}{l}123.87 \pm \\
1.20^{+++}\end{array}$ & $122.62 \pm 2.20^{+++}$ & - & - & - & $99.67 \pm 1.82^{* * *}$ & $\begin{array}{l}119.62 \pm \\
1.17^{+++}\end{array}$ \\
\hline $\begin{array}{l}\text { Insulin }(\mathrm{ng} / \\
\mathrm{mL})\end{array}$ & $0.74 \pm 0.06$ & $1.99 \pm 0.18^{+++}$ & $1.31 \pm 0.14^{+*}$ & - & - & - & $1.40 \pm 0.12^{+*}$ & $1.56 \pm 0.14^{++}$ \\
\hline HOMA & $3.34 \pm 0.29$ & $10.86 \pm 0.95^{+++}$ & $7.06 \pm 0.70^{+}{ }^{*}$ & - & - & - & $6.17 \pm 0.53^{+}{ }^{*}$ & $8.34 \pm 0.83^{++}$ \\
\hline AI & $\begin{array}{c}115.78 \pm \\
3.73\end{array}$ & $\begin{array}{l}226.47 \pm \\
2.09^{+++}\end{array}$ & $225.94 \pm 4.58^{+++}$ & & & & $129.33 \pm 2.92^{+}$, & $\begin{array}{c}154.74 \pm \text { 士 } \\
2.75^{+++* * * * \# \#}\end{array}$ \\
\hline
\end{tabular}

Data are expressed as means \pm SEM.

${ }^{+} P<0.05,{ }^{++} P<0.01,{ }^{+++} P<0.001$ vs. normal control group.

${ }^{*} P<0.05,{ }^{* *} P<0.01,{ }^{* * *} P<0.001$ vs. HFD group.

${ }^{\#} P<0.05,{ }^{\# \#} P<0.01,{ }^{\# \# \#} P<0.001$ vs. Sham group. 
groups showed no significant body weight changes relative to the NC group. The PC and eB3 ( $P$ $<0.001)$, and eB2 $(P<0.01)$ groups showed significant higher body weight vs. Sham (Table 1$)$.

\section{Effect of betanin on biochemical parameters}

TG, phospholipid, TL, LDL-C, and VLDL showed a significant increase in the HFD and Sham groups vs. NC group $(P<0.001)$. On the other hand, these parameters were significantly decreased in the treated groups, approaching normal values at the highest dose of betanin (TG to 79.47 and VLDL to $17.64 \mathrm{mg} / \mathrm{dl}$ ); the two lower doses of betanin also reduced these levels, but to a lesser extent. HDL-C levels were markedly reduced in the HFD and Sham, but significantly increased in the treated groups, especially in the eB3 and PB groups. TC levels were markedly increased in the HFD and Sham, and significantly reduced in the treated groups except for eB1. TP levels were markedly increased in the HFD and Sham, but reduced only in the PC group (to $2.6 \mathrm{mg} / \mathrm{dl}$ ), and differences seen in the $\mathrm{eB} 3$ and $\mathrm{PB}$ groups were not significant. TP levels did not show any decrease in the eB1 and eB2 groups. Fasting blood sugar (FBS), insulin levels and insulin resistance were significantly increased in the HFD and Sham vs. NC group. These parameters were increased respectively in the HFD group and remained elevated in Sham. These factors were markedly reduced in the eB3group (FBS to $99.67 \mathrm{mg} / \mathrm{dl}$, insulin to $1.4 \mathrm{mg} / \mathrm{dl}$, and HOMA to $6.17 \mathrm{mg} / \mathrm{dl}$ ) and the apparent decrease in PB group was not significant. Decrease of insulin level and insulin resistance was more significant in Sham than in the HFD group. AI was markedly increased in HFD and Sham vs. NC group and was decreased to $\sim 129$ by high-dose
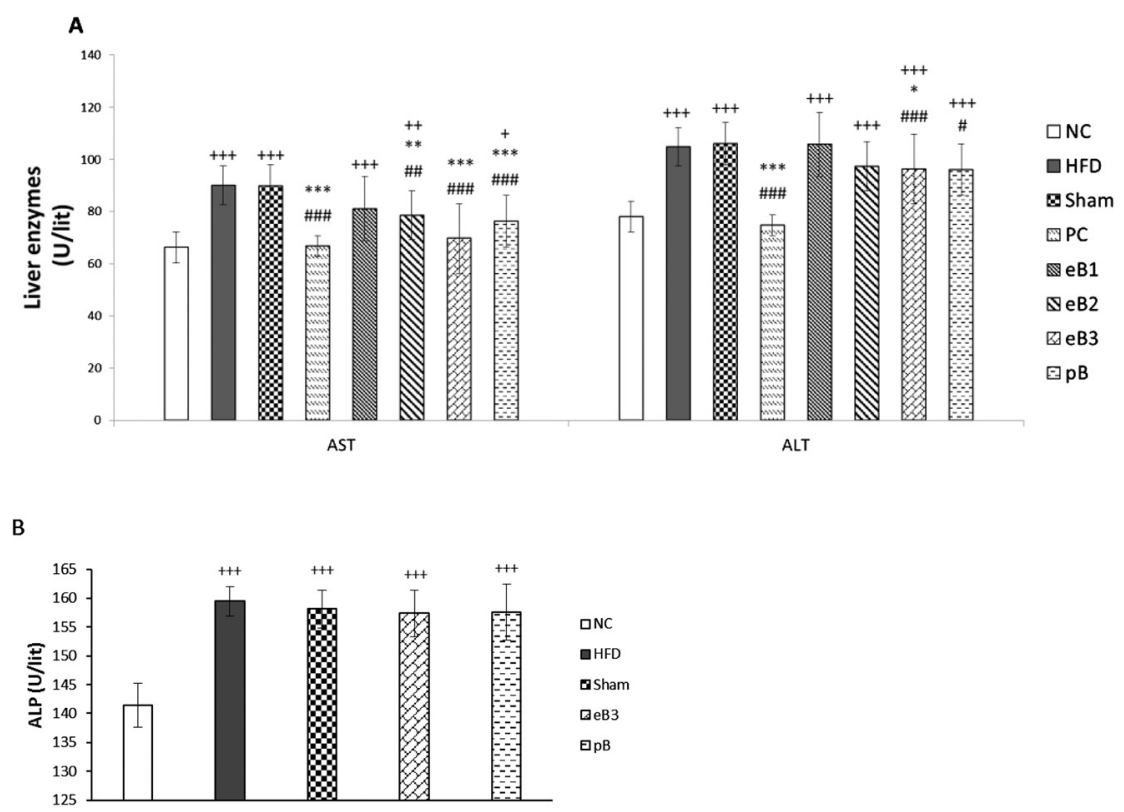

Figure 1. Effects of betanin on the levels of liver enzymes (A: AST\&ALT, B: ALP) in HFR-fed mice. Data are expressed as the means \pm SEM. ${ }^{+} P<0.05,{ }^{++} P<0.01,{ }^{+++} P<0.001$ vs. normal control group. ${ }^{* *} P<$ $0.01,{ }^{* * *} P<0.001$ vs. HFD group. ${ }^{\#} P<0.05,{ }^{\# \#} P<0.01,{ }^{\# \# \#} P<0.001$ vs. Sham group 
Table 3. Effects of betanin on liver antioxidant enzymes in HFR-fed mice

\begin{tabular}{|c|c|c|c|c|c|c|c|c|}
\hline Groups & $\mathrm{NC}$ & HFD & Sham & $\mathrm{PC}$ & $\mathrm{eB} 1$ & $\mathrm{eB} 2$ & eB3 & $\mathrm{PB}$ \\
\hline \multicolumn{9}{|l|}{ Parameters } \\
\hline $\begin{array}{l}\text { MDA } \\
\qquad(\mathrm{nmol} / \mathrm{g})\end{array}$ & $\begin{array}{c}4.08 \pm \\
0.11\end{array}$ & $\begin{array}{c}6.59 \pm \\
0.07^{+++}\end{array}$ & $\begin{array}{c}6.37 \pm \\
0.15^{+++}\end{array}$ & $\begin{array}{c}4.33 \pm \\
0.10^{* * *}, \# \#\end{array}$ & $\begin{array}{c}6.71 \pm \\
0.09^{+++}\end{array}$ & $\begin{array}{c}4.91 \pm \\
0.13^{+++},,,\end{array}$ & $\begin{array}{c}4.49 \pm \\
0.14^{* * *},\end{array}$ & $\begin{array}{c}3.78 \pm \\
0.07^{* * * * \# \#}\end{array}$ \\
\hline $\operatorname{SOD}(\mu / \mathrm{mg})$ & $\begin{array}{c}18.96 \pm \\
0.83\end{array}$ & $\begin{array}{l}14.20 \pm \\
0.46^{+++}\end{array}$ & $\begin{array}{c}12.33 \pm \\
0.13^{+++}\end{array}$ & - & - & - & $\begin{array}{c}15.50 \pm \\
0.12^{+++, \# \#}\end{array}$ & $\begin{array}{l}17.62 \pm \\
0.16^{* * *},\end{array}$ \\
\hline $\mathrm{CAT}(\mu / \mathrm{mg})$ & $\begin{array}{c}53.63 \pm \\
0.12\end{array}$ & $\begin{array}{l}42.69 \pm \\
0.91^{+++}\end{array}$ & $\begin{array}{l}41.12 \pm \\
1.45^{+++}\end{array}$ & - & - & - & $\begin{array}{c}47.47 \pm \\
0.17^{+++},{ }^{* *}\end{array}$ & $\begin{array}{c}52.07 \pm \\
0.55^{* * *} \text { \#\#\# }\end{array}$ \\
\hline $\begin{array}{l}\text { FRAP } \\
\qquad \begin{array}{l}(\mu \mathrm{mol} / \\
\mathrm{mg})\end{array}\end{array}$ & $\begin{array}{c}18.92 \pm \\
0.08\end{array}$ & $\begin{array}{l}14.42 \pm \\
0.26^{+++}\end{array}$ & $\begin{array}{l}14.56 \pm \\
0.14^{+++}\end{array}$ & $\begin{array}{c}16.80 \pm \\
0.18^{+++},,\end{array}$ & $\begin{array}{l}15.13 \pm \\
0.17^{+++}\end{array}$ & $\begin{array}{c}16.49 \pm \\
0.22^{+++},{ }^{* * *}, \ldots \#\end{array}$ & $\begin{array}{c}16.75 \pm \\
0.17^{+++},,,\end{array}$ & $\begin{array}{c}16.51 \pm \\
0.25^{+++},{ }^{* * *}, \# \# \#\end{array}$ \\
\hline
\end{tabular}

Data are expressed as means \pm SEM.

${ }^{++} P<0.001$ vs. normal control group.

${ }^{*} P<0.05,{ }^{* *} P<0.01,{ }^{* * *} P<0.001$ vs. HFD group.

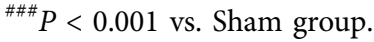


betanin treatment and to $\sim 155$ by co-administration of high-dose betanin with the high-fat diet $(P<0.001)$ (Table 2).

Levels of AST, ALT and ALP were significantly increased in the HFD and Sham groups vs. NC group $(P<0.001)$ (Fig. 1). Trans-chalcone restored AST and ALT levels to normal. Treatment with betanin in both treatment and protective modes resulted in a significant decrease in the amount of AST and ALT (except for the eB1 group) vs. HFD and Sham (Fig. 1A). ALP levels did not show a significant decrease in treated groups (Fig. 1B). The levels of SOD, CAT, MDA and ferric reducing ability of plasma (FRAP) were affected by HFR. Compared with control, HFD and Sham, decreases were seen in SOD, CAT and FRAP (Table 3). In comparison, the serum levels of SOD, CAT and FRAP showed a significant increase, whereas MDA exhibited a significant reduction in PC and betanin-treated groups in a dose-dependent manner (except for eB1 group) (Table 3). Serum leptin was found to increase considerably, doubled in HFD and was elevated in Sham; it was significantly reduced by consumption of a higher dose of betanin $(20 \mathrm{mg} / \mathrm{kg})$, but was ineffective in the protective mode (Fig. $2 \mathrm{~A})$. Serum adiponectin levels were significantly reduced in the HFD and Sham and remarkably increased in the $\mathrm{PC}$ and $\mathrm{eB} 3$ groups. This increase was not considerable in the other treated groups (Fig. 2B). TNF- $\alpha$ was markedly enhanced in the HFD and Sham, but did not show a significant decrease in the eB3 and PB groups vs. HFD and Sham (Fig. 2C).

\section{Histopathological assessment}

Liver tissue sections were stained with hematoxylin \& eosin (Supplementary Fig. 1) and Masson's trichrome (Supplementary Fig. 2). Liver sections of the control group showed unremarkable tissue with preserved architecture (Fig. S1A, Fig. S2A). Tissue steatosis (Fig. S1B, C)

A

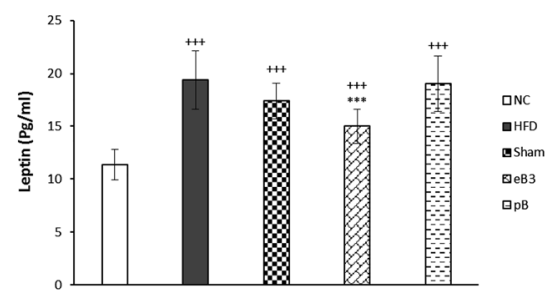

C

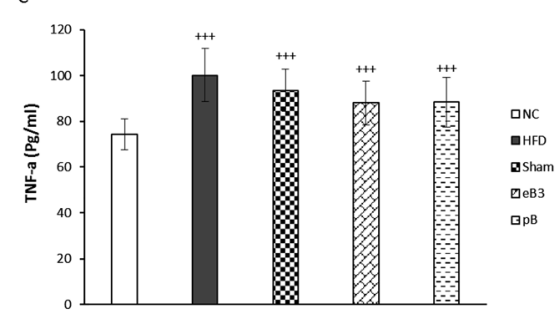

B

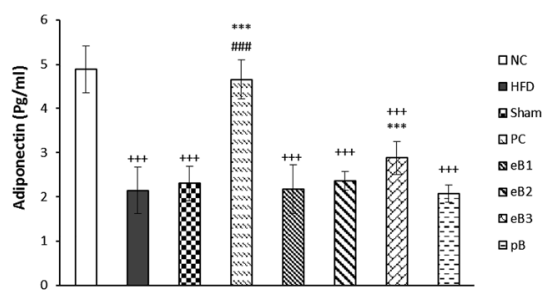

Figure 2. Effects of betanin on the serum levels of leptin (A), adiponectin (B) and TNF- $\alpha$ (C) in HFR-fed mice. Data are expressed as the means \pm SEM. ${ }^{+++} P<0.001$ vs. normal control group. ${ }^{* * *} P<0.001$ vs. HFD group. ${ }^{\# \#} P<0.01,{ }^{\# \# \#} P<0.001$ vs. Sham group 


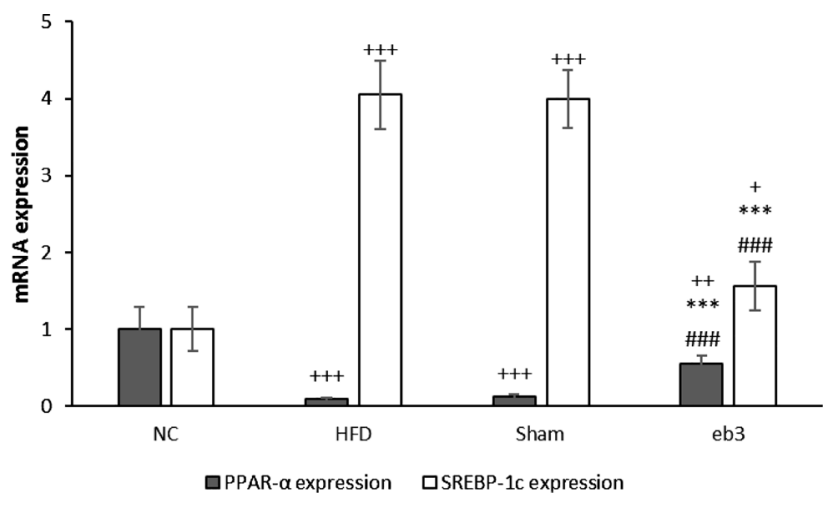

Figure 3. Effects of betanin on the expression levels of PPAR- $\alpha$ and SREBP-1c in HFR-fed mice. Data are expressed as the means \pm SEM. ${ }^{+} P<0.05,{ }^{++} P<0.01,{ }^{+++} P<0.001$ vs. normal control group. ${ }^{* * *} P<0.001$ vs. HFD group. ${ }^{\# \# \#} P<0.001$ vs. Sham group

and fibrosis (Fig. S2 B, C) were confirmed by histological analysis of the HFD group liver tissue. HFD group sections showed moderate microvesicular and macrovesicular steatosis (score 3), ballooning degeneration (score 3), Mallory-Denk bodies, accumulation of inflammatory cells (score 3), moderate necroinflammatory activity (Fig. S1B, C) and moderate pericellular, perivascular and bridging fibrosis (score 3) (Fig. S2 B, C). The Sham group showed mild microvesicular and macrovesicular steatosis (score 1), ballooning degeneration (score 3) (Fig. S1D) and pericellular and periportal fibrosis (score 2) (Fig. S2D). The treated groups showed normal histology (Fig. S1E-I, Fig. S2 E-I). Liver sections of PC and eB1, eB2 and eB3 groups seemed reversed to normal conditinon, but the PC group showed inflammation score 1 [18]. Liver sections of $\mathrm{PB}$ improved moderatly.

\section{PPAR- $\alpha$ and SREBP-1c mRNA expression level}

PPAR- $\alpha$ and SREBP-1c expression levels showed a marked decrease and increase, respectively, in the HFD and Sham groups in comparison with the NC group $(P<0.001)$, whereas treatment with betanin improved their expression in the eB3 group with a significant difference from the HFD and Sham groups $(P<0.001)$ (Fig. 3).

\section{DISCUSSION}

Based on our results, some of the groups have shown a notable decrease in their body weight compared with NC group. Due to the presence of some components in HFR such as sodium deoxycholate, Tween 80 and propylene glycol, this diet did not cause a body weight gain in the mice. Similarly, MCD (methionine and choline deficient) diet, which is used for preclinical NASH studies, is shown to cause important weight loss [23]. Sodium deoxycholate is a bile salt that is used as lipid and phospholipid solubilizer [31]. This component facilitates fat absorption in the intestine. Tween 80 is used as a co-emulsifier for HFD emulsion [28]. Propylene glycol, as an anti-ketosis agent, is able to collect blood FFAs that were released by sodium deoxycholate 
and stored in the liver [3]. The body weight of the eB3 group showed no significant changes in comparison with the NC group (Table 1). It seems that betanin is effective at a higher dose (20 $\mathrm{mg} / \mathrm{kg}$ ) in the normalization of body weight. This finding is consistent with previous reports about betanin-rich djulis grains and beetroot crisps, in rats receiving dyslipidemic diets $[38,40]$.

In the current study, HFR intake caused an increase in the levels of TG, TC, phospholipids, TL, LDL-C, and VLDL, whereas HDL-C was decreased. These changes are also observed in NAFLD and NASH. HFR intake raised TP levels similar to the observations in a recent study [6], but betanin was not effective in this case when administered at 5,10 or $20 \mathrm{mg} / \mathrm{kg}$ for 3 weeks.

Our results showed that betanin remarkably increased HDL-C levels and significantly lowered other lipid profile parameters. Trans-chalcone at $24 \mathrm{mg} / \mathrm{kg}$ decreased notably TG, TC, VLDL, and TP levels. This compound is a precursor of flavonoids and exhibits antioxidant and anti-inflammatory effects. According to a previous report, trans chalcone significantly reduced the levels of TG and TC in cholesterol-fed NMRI mice at 12 and $24 \mathrm{mg} / \mathrm{kg}$ [17]. In another study, trans-chalcone $(12 \mathrm{mg} / \mathrm{kg})$ did not decrease remarkably these parameters in obese mice [16]. Previous studies have demonstrated that components containing betanin such as djulis and red beet could reduce cholesterol, triglyceride and LDL levels and elevate levels of HDL [25, 38, 40]. Overall, betanin exerted beneficial anti-hyperlipidemic effects on the lipid profilein both treatment and protection mode.

Insulin resistance is linked to the development of NASH and considered to be one of its markers. It has a key role in the pathogenesis of NASH and is involved in hepatic lipid retention [5]. Similarly to previous research, our results indicated that HFR consumption in mice leads to a significant increase in FBS, insulin and HOMA index vs. normal group [5]. Our findings showed a remarkable decrease in FBS, insulin, and HOMA values upon treatment with betanin. Other studies have reported that administration of betacyanins to high-fat diet-fed mice and of betanin to high-fructose-fed rats ameliorates glucose, insulin, insulin resistance, and obesity [14, 33]. Leptin is involved in insulin resistance that is increased by HFR consumption, whereas betanin administration decreased leptin levels and, consequently, attenuated insulin resistance. Based on these data, betanin showsan anti-insulin resistance effect. Since dyslipidemia and oxidative stress enhance insulin resistance [37], it seems that the anti-insulin resistance effect is related to the anti-hyperlipidemia and anti-oxidant effects of betanin. The anti-diabetic effects of red beet have been demonstrated in previous reports [25]. In this regard, the highest dose of betanin in the treated groups was more effective (compared with the protective mode).

In the current research, HFR significantly increased AI in HFD and Sham. High fat results in oxidative stress, which increases LDL oxidation that is an important contributor to atherogenesis. Antioxidants, including betalains, would thus counteract atherosclerosis [40]. Betanin can reach the circulation and distribute in LDL and red blood cells, where the molecule is presumably involved in antioxidant protection [22]. A previous study has shown that betanin attenuates LDL oxidation [2]. Parallel with these findings, our study showed that betanin remarkably decreased AI and improved antioxidant enzyme levels in our treated groups. In this case, both treatment and protective modes were effective.

By administration of HFR, MDA was enhanced and SOD, CAT, and FRAP decreased significantly. Oxidative stress is responsible for triggering ROS which is a risk factor in the progression of hepatic diseases and lipid peroxidation within the cell, which ultimately results in the formation of MDA [17]. Antioxidant enzymes such as SOD and CAT protect cells against 
oxidative damage and have a detoxifying effect. Betanin can induce detoxification and the expresssion of antioxidant enzymes by activation of the nuclear erythroid-2-related factor 2 [20]. Antioxidant, anti-radical and anti-inflammatory effects of betanin have been described in previous studies. Betanin is also able to inhibit lipid peroxidation through inhibition of nitrogen dioxide and lipoperoxyl radical-scavenging activity [2]. In the present study, betanin attenuated oxidative stress caused by HFR, displaying decreased MDA and increased SOD and CAT and FRAP levels. These results indicate betanin's protective effect, which parallels previous reports about betalains exhibiting free radical scavenging and antioxidant activities [7, 15].

Serum AST, ALT, and ALP levels are elevated in NASH [12]. In the current study, HFD and Sham showed an increase in the plasma levels of these parameters, whereas betanin treatment reduced AST and ALT, in accordance with previous studies [7, 15]. In this regard too, the compound may act by influencing antioxidant defenses. ALP levels did not show a significant decrease in treated groups. In previous studies, administration of red pitaya juice supplementation to high-carbohydrate, high-fat diet-fed fed rats and of table beet powder to rats with fatty liver decreased ALP levels $[30,32]$. It seems that a higher dose of betanin is more effective. In this research, trans-chalcone decreased AST, ALT, and MDA levels and increased FRAP significantly.

Adipokines have a role in the pathogenesis of NASH, where lower adiponectin levels are correlated with the severity of the disease, through their metabolic and pro-/anti-inflammatory activity. According to our results, like in other previous studies, HFR caused a notable reduction of adiponectin and increase of leptin and TNF- $\alpha$ levels [39]. At the highest dose used, betanin significantly increased adiponectin and decreased leptin, and was more effective in the treated groups compared with the protective mode. Also, trans-chalcone markedly increased adiponectin in comparison with HFD and Sham. This result is in parallel with a study on transchalcone at 12 and $24 \mathrm{mg} / \mathrm{kg}$ doses [17]. Haizhao Song et al. have reported betacyanins of pitaya peel to increase the level of adiponectin and the hepatic expression of its receptor, AdipoR2 (adiponectin receptor 2) [33]. Adiponectin improves the regulation of fatty acid and glucose metabolism, and AdipoR2 activates the PPAR- $\alpha$ ligand as well as fatty acid oxidation and glucose uptake by adiponectin [39].

Our results did not show a significant effect for betanin on TNF- $\alpha$ at either dose. Another study on an acute lung injury model has shown a decrease in TNF- $\alpha$ levels by doses of 25 and $100 \mathrm{mg} / \mathrm{kg}$ betanin [13]. According to other data, pro-inflammatory cytokines such as TNF- $\alpha$ were decreased by beet root ethanolic extract in gentamicin-induced nephrotoxicity of rodent model, by betalain-rich oral capsules made from beetroot extracts in osteoarthritic patients, and also by betalain in edema models [9, 24, 27].

The PPAR- $\alpha$ gene plays a crucial role in the balance of lipids and glucose, and its expression is remarkably reduced in NAFLD and NASH. PPAR- $\alpha$ agonists have been suggested to act against NASH [34]. Overexpression of SREBP-1c can lead to NAFLD/NASH (19). Inhibition of SREBP can treat diseases associated with abnormal lipid metabolism, such as NASH [42]. mRNA and protein levels of SREBP-1c are mainly regulated by insulin [10]. HFR was shown here to down-regulate PPAR- $\alpha$ and up-regulate SREBP-1c, whereas betanin treatment corrected these effects to some extent. Betanin may act by antioxidant activity and by modifying insulin and lipid profiles.

Based on our histological analysis of liver, HFR markedly induced lipid accumulation by hepatocytes and caused inflammation and NASH with fibrosis, whereas lipid accumulation, 
inflammation and fibrosis were alleviated by betanin. Haizhao Song et al.'s findings concerning the effects of betacyanins were in accordance with our results [33]. In the current study, steatosis and hepatocyte ballooning were markedly decreased after treatment with betanin. These findings suggest that betadin, in a dose-dependent way, helped the restoration of hepatocytes by improving the activity of antioxidant enzymes and the lipid profile, ameliorating adiponectin and leptin levels, and by up-regulating PPAR- $\alpha$ and down-regulating SREBP-1c.

\section{CONCLUSION}

In conclusion, betanin has antioxidant, anti-insulin resistance and anti-hyperlipidemic effects and could alleviate steatohepatitis. The effect is exerted through down-regulation of SREBP-1c, up-regulation of PPAR- $\alpha$ in liver tissue, increases in antioxidant enzyme levels, leptin reduction, adiponectin enhancement, lowering insulin resistance, and modulation of lipid profiles. We suggest that betanin could be considered as a potential therapeutic agent for NAFLD/NASH.

Funding: No funding is to be reported for this study.

Conflict of interests: The authors declare to have no conflict of interests.

\section{ACKNOWLEDGMENTS}

This study was performed in the Laboratory Complex of the Science and Research Branch of Azad University.

\section{APPENDIX A. SUPPLEMENTARY DATA}

Supplementary data to this article can be found online at https://doi.org/10.1556/2060.2020. 00001

\section{REFERENCES}

1. Al-Busafi SA, Bhat M, Wong P, Ghali P, Deschenes M. Antioxidant therapy in nonalcoholic steatohepatitis. Hepat Res Treat. 2012;2012:947575.

2. Allegra M, Tesoriere L, Livrea MA. Betanin inhibits the myeloperoxidase/nitrite-induced oxidation of human low-density lipoproteins. Free Radic Res. 2007;41:335-41.

3. Bjerre-Harpøth V, Storm AC, Eslamizad M, Kuhla B, Larsen M. Effect of propylene glycol on adipose tissue mobilization in postpartum over-conditioned Holstein cows. J. Dairy Sci. 2015;98:8581-96.

4. Burri L, Thoresen GH, Berge RK. The role of PPAR activation in liver and muscle. PPAR Res. 2010;2010:542359.

5. Chitturi S, Abeygunasekera S, Farrell GC, Holmes-Walker J, Hui JM, Fung C, et al. NASH and insulin resistance: insulin hypersecretion and specific association with the insulin resistance syndrome. Hepatology. 2002;35:373-9. 
6. Cho J-H, Namgung J-S, Lee J, Moon D-H, Lee H-K. Analysis of biochemical markers related to Fatty liver patients. J Phys Ther Sci. 2014;26:1865-8.

7. Clifford T, Howatson G, West DJ, Stevenson EJ. The potential benefits of red beetroot supplementation in health and disease. Nutrients. 2015;7:2801-22.

8. Dowman JK, Tomlinson J, Newsome P. Pathogenesis of non-alcoholic fatty liver disease. QJM. 2010;103: 71-83.

9. El Gamal AA, AlSaid MS, Raish M, Al-Sohaibani M, Al-Massarani SM, Ahmad A, et al. Beetroot (Beta vulgaris L.) extract ameliorates gentamicin-induced nephrotoxicity associated oxidative stress, inflammation, and apoptosis in rodent model. Mediators Inflamm. 2014;2014:983952.

10. Foretz M, Pacot C, Dugail I, Lemarchand P, Guichard C, le Lièpvre X, et al. ADD1/SREBP-1c is required in the activation of hepatic lipogenic gene expression by glucose. Mol Cell Biol. 1999;19:3760-8.

11. Gliszczyńska-Świgło A, Szymusiak H, Malinowska P. Betanin, the main pigment of red beet: molecular origin of its exceptionally high free radical-scavenging activity. Food Addit Contam. 2006;23:1079-87.

12. Hall P, Cash J. What is the real function of the liver 'function' tests? Ulster Med J. 2012;81:30-6.

13. Han J, Ma D, Zhang M, Yang X, Tan D. Natural antioxidant betanin protects rats from paraquat-induced acute lung injury interstitial pneumonia. Biomed Res Int. 2015;2015:608174.

14. Han J, Tan C, Wang Y, Yang S, Tan D. Betanin reduces the accumulation and cross-links of collagen in highfructose-fed rat heart through inhibiting non-enzymatic glycation. Chem Biol Interact. 2015;227:37-44.

15. Han J, Zhang Z, Yang S, Wang J, Yang X, Tan D. Betanin attenuates paraquat-induced liver toxicity through a mitochondrial pathway. Food Chem Toxicol. 2014;70:100-6.

16. Jalalvand F, Amoli MM, Yaghmaei P, Kimiagar M, Ebrahim-Habibi A. Acarbose versus trans-chalcone: comparing the effect of two glycosidase inhibitors on obese mice. Arch. Endocrinol Metab. 2015;59:202-9.

17. Karkhaneh L, Yaghmaei P, Parivar K, Sadeghizadeh M, Ebrahim-Habibi A. Effect of trans-chalcone on atheroma plaque formation, liver fibrosis and adiponectin gene expression in cholesterol-fed NMRI mice. Pharmacol Rep. 2016;68:720-7.

18. Kleiner DE. Histopathology, grading and staging of nonalcoholic fatty liver disease. Minerva Gastroenterol Dietol. 2018;64:28-38.

19. Kohjima M, Enjoji M, Higuchi N, Kato M, Kotoh K, Yoshimoto T, et al. Re-evaluation of fatty acid metabolism-related gene expression in nonalcoholic fatty liver disease. Int J Mol Med. 2007;20:351-8.

20. Krajka-Kuźniak V, Paluszczak J, Szaefer H, Baer-Dubowska W. Betanin, a beetroot component, induces nuclear factor erythroid-2-related factor 2-mediated expression of detoxifying/antioxidant enzymes in human liver cell lines. Br J Nutr. 2013;110:2138-49.

21. Lee J-H, Kang HS, Park HY, Moon Y-A, Kang YN, Oh B-C, et al. PPAR $\alpha$-dependent Insig2a overexpression inhibits SREBP-1c processing during fasting. Sci Rep. 2017;7:9958.

22. Livrea MA, Tesoriere L. Lipoperoxyl radical scavenging and antioxidative effects of red beet pigments. In: Neelwarne B, editor. Red beet biotechnology. Boston, MA: Springer; 2013. pp. 105-24.

23. Machado MV, Michelotti GA, Xie G, de Almeida TP, Boursier J, Bohnic B, et al. Mouse models of diet-induced nonalcoholic steatohepatitis reproduce the heterogeneity of the human disease. PLoS One. 2015;10:e0127991.

24. Martinez RM, Longhi-Balbinot DT, Zarpelon AC, Staurengo-Ferrari L, Baracat MM, Georgetti SR, et al. Antiinflammatory activity of betalain-rich dye of Beta vulgaris: effect on edema, leukocyte recruitment, superoxide anion and cytokine production. Arch Pharm Res. 2015;38:494-504.

25. Murthy KNC, Manchali S. Anti-diabetic potentials of red beet pigments and other constituents. In: Neelwarne B, editor. Red beet biotechnology. Boston, MA: Springer; 2013. pp. 155-74.

26. Pawlak M, Lefebvre P, Staels B. Molecular mechanism of PPAR $\alpha$ action and its impact on lipid metabolism, inflammation and fibrosis in non-alcoholic fatty liver disease. J Hepatol. 2015;62:720-33. 
27. Pietrzkowski Z, Nemzer B, Spórna A, Stalica P, Tresher W, Keller R, et al. Influence of betalain-rich extract on reduction of discomfort associated with osteoarthritis. New Medicine. 2010;1:12-7.

28. Prabhakar K, Afzal SM, Surender G, Kishan V. Tween 80 containing lipid nanoemulsions for delivery of indinavir to brain. Acta Pharm Sin B. 2013;3:345-53.

29. Qu H-Q, Li Q, Rentfro AR, Fisher-Hoch SP, McCormick JB. The definition of insulin resistance using HOMA-IR for Americans of Mexican descent using machine learning. PLoS One. 2011;6:e21041.

30. Ramli NS, Brown L, Ismail P, Rahmat A. Effects of red pitaya juice supplementation on cardiovascular and hepatic changes in high-carbohydrate, high-fat diet-induced metabolic syndrome rats. BMC Complement Altern Med. 2014;14:1.

31. Rotunda AM, Suzuki H, Moy RL, Kolodney MS. Detergent effects of sodium deoxycholate are a major feature of an injectable phosphatidylcholine formulation used for localized fat dissolution. Dermatol Surg. 2004;30: $1001-8$.

32. Sárdi É, Stefanovits-Bányai É, Kocsis I, Takács-Hájos M, Fébel H, Blázovics A. Effect of bioactive compounds of table beet cultivars on alimentary induced fatty livers of rats. Acta Alimentaria. 2009;38:267-80.

33. Song $\mathrm{H}$, Chu Q, Xu D, Xu Y, Zheng X. Purified betacyanins from hylocereus undatus peel ameliorate obesity and insulin resistance in high-fat-diet-fed mice. J Agric Food Chem. 2015;64:236-44.

34. Souza-Mello V. Peroxisome proliferator-activated receptors as targets to treat non-alcoholic fatty liver disease. World J Hepatol. 2015;7:1012-9.

35. Surh YJ. Cancer chemoprevention with dietary phytochemicals. Nat Rev Cancer. 2003;3:768-80.

36. Tailleux A, Wouters K, Staels B. Roles of PPARs in NAFLD: potential therapeutic targets. Biochim Biophys Acta. 2012;1821:809-18.

37. Tangvarasittichai S. Oxidative stress, insulin resistance, dyslipidemia and type 2 diabetes mellitus. World J Diabetes. 2015;6:456-80.

38. Tsai PJ, Hsiao SM, Chaung HC, Hong CZ, Wang CL. The LDL-cholesterol-lowering Effects of Nano-particled Djulis Grains. In: Proceedings of International Conference on Bioscience, Biochemistry and Bioinformatics (ICBBB 2011). Singapore: IACSIT Press; 2011. pp. 218-21.

39. Tsochatzis EA, Papatheodoridis GV, Archimandritis AJ. Adipokines in nonalcoholic steatohepatitis: from pathogenesis to implications in diagnosis and therapy. Mediators Inflamm. 2009;2009:831670.

40. Wroblewska M, Juskiewicz J, Wiczkowski W. Physiological properties of beetroot crisps applied in standard and dyslipidaemic diets of rats. Lipids Health Dis. 2011;10:1.

41. Ziamajidi N, Khaghani S, Hassanzadeh G, Vardasbi S, Ahmadian S, Nowrouzi A, et al. Amelioration by chicory seed extract of diabetes-and oleic acid-induced non-alcoholic fatty liver disease (NAFLD)/nonalcoholic steatohepatitis (NASH) via modulation of PPAR $\alpha$ and SREBP-1. Food Chem Toxicol. 2013;58: 198-209.

42. Zimmer M, Bista P, Benson EL, Lee DY, Liu F, Picarella D, et al. CAT-2003: A novel sterol regulatory element-binding protein inhibitor that reduces steatohepatitis, plasma lipids, and atherosclerosis in apolipoprotein E* 3-Leiden mice. Hepatol Commun. 2017;1:311-25. 